\title{
Ethical dilemmas of brain failure in the elderly
}

\author{
GEORGE S ROBERTSON
}

Medical ethics has come of age in the past year or two as medical and non-medical people alike have been drawn into discussions of the morality or immorality of possible solutions to immensely complex ethical dilemmas. Abortion is an example of an ethical problem which has been faced and "solved" but which continues to offend even though the ethical codes on abortion have been distilled from years of medical, legal, philosophical, and religious debate.

The care of infants born with congenital handicaps has provoked equally strong emotions. Important as these problems are, those posed by our elderly citizens, particularly those with brain failure, are assuming even greater urgency. The important lesson is that the dilemmas are becoming more predictable. In the elderly they will arise from the combination of reduced premature deaths in the young and middle aged, and a projected increase of some $42 \%$ in the number over the age of 85 for the years 1971-91.2 In people over 80 the incidence of senile dementia is about $20 \%$, and it is estimated that within the next five years there will be 3000 elderly demented people per 250000 of the population. ${ }^{3}$ In this age group only $3.8 \%$ of cases are likely to have a treatable cause for their dementia ${ }^{4}$ and the prognosis in this type of brain failure approximates to that of the more malignant forms of cancer. Thus the two year mortality in senile dementia is $50 \%{ }^{5}$ but in the meantime many patients may have socially disturbing symptoms. A study in six old people's homes, designed and staffed to cater for the physically dependent elderly, has shown that half of the residents were probably demented and that one third showed evidence of disturbed, interfering, or aggressive behaviour. ${ }^{7}$

\footnotetext{
Department of Anaesthetics, Aberdeen Royal Infirmary, Aberdeen AB9 22B

GEORGE S ROBERTSON, MD, FRARCs, consultant anaesthetist
}

\section{Fear of senility and indignity}

The socially unacceptable behaviour of demented patients is perhaps the object of the greatest health related fear within an elderly population. Kellet states that in discussion with the elderly, "Nowhere is fear greater than in the prospect of senility." The sociomedical significance of senility is emphasised by the statement that, "The effects of chronic physical illness tail into insignificance when compared with the burden of patients with dementia."?

To the aging, dementia is synonymous with a loss of dignity, and this is a recurring feature of some hundreds of letters on this subject I have received in recent months from elderly people. Dignity is hard to define, but the perception of indignity clearly depends on the observed and the observer. Nakedness and incontinence, for example, are perceived quite differently by a mother in her baby and by a daughter in her mother. Similarly, incontinence in a geriatric ward may be regarded as normal by nurses and doctors but may cause untold distress to close relatives.

McCall Smith in an elegant essay on "Dignity and medical procedures" argues that there are circumstances in which the maintenance of medical treatment at all costs and the duty of doctors to do everything in their power to prolong life "can fairly be said to affront the dignity of the patient." ${ }^{8} \mathrm{He}$ goes on to say that dignity can be "one of the features which lend worth to existence, almost a sine qua non of a satisfactory life."

There is evidence, often graphically supported by press and television documentaries, that many of the features of senility as seen in brain failure (mainly dementia and hemiplegic stroke) are medically unremarkable but are disturbing or offensive to those approaching old age and to the relatives of elderly patients. Lay people, unaccustomed to irrational and antisocial behaviour, may react with extreme sensitivity to the changed appearance and personality of a close relative. A common sequel is reference to a "cabbage-like existence" and the wish that they in turn could somehow spare their offspring or spouses the unsavoury features of senility. 
Attempts have been made to give expression to the wishes of individuals for some assurance of dignity in the process of dying. The Voluntary Euthanasia Society has made repeated and unsuccessful attempts to gain recognition of the right of the individual to choose the timing and, in some degree, the process of death in relation to advanced, incurable illness. This concerns mainly malignant disease, and the rapid and welcome growth in hospice care in recent years must answer much of the case made by the Voluntary Euthanasia Society. The booklet issued on request to members of the society may give doctors even greater cause for concern. It is morbidly explicit and offers clear opportunities for abuse at the hands of those who may be psychiatrically disturbed. In practical terms it is difficult to see how the various methods of "self deliverance" (a euphemism for suicide) could be implemented by patients with brain failure. The reasons for the booklet's existence, however, must give doctors cause to question the adequacy of their role in the terminal care of some patients.

\section{Written declarations of wish}

The Voluntary Euthanasia Society was the first body to promote the concept that patients might retain a degree of control in terminal illness when unable to communicate, by signing a written statement while in good health. Some 9000 members in England and Wales have signed the declaration, but because of vague and emotional phrasing, there may be difficulties of interpretation. Thus the declaration requests natural dying to be allowed, "If there is no reasonable prospect of my recovery from physical illness or impairment expected to cause me severe distress ..." (but should this apply to, for example, osteoarthritis ?), ". . . or render me incapable of rational existence. ..." What exactly does this mean ? Though the Voluntary Euthanasia Society document is probably intended to apply mainly to terminal malignant disease, it has already been argued that the deficiencies in this aspect of practice are in the process of being rectified.

The concept of a prior written statement has been pursued further in the USA, and in 13 states legislation exists which declares the legal validity of living wills. Unfortunately, the terminology may still be difficult to interpret, and it has been suggested that written instructions need to be supplemented by discussion between prospective patients, their doctors, and relatives. ${ }^{\circ}$ An unpleasant feature of the American living will is the possibility that a lawsuit might follow if a doctor failed to carry out the patient's written wishes. The American legislature may have seen fit to endorse the concept of prior written wishes because of the greater public awareness of patients' rights, which seem to gain expression in the excessive use of litigation. In addition to the much larger numbers of the elderly in America, there is a greater public awareness of the potential for prolonging life which is offered by modern technology and pharmacology.

The relative attitudes of British and American doctors to written wishes and guidelines have been thoughtfully analysed recently by Bayliss, who comes down on the side of "unhurried clinical judgment, sympathy, understanding, and mutual trust" rather than "abstract principles and printed policy statements."10 It has to be said that these conclusions reflect largely medical as distinct from lay opinion, and they address the problems of cardiopulmonary resuscitation in acute medicine and surgery rather than those of illness in the elderly. Earlier ethical speculation on the right to life concluded that the time for guidance to doctors should not be delayed; what is at stake are "fundamental moral problems for whose solution ad hoc or empirical decisions, common sense and a kind heart are, alas, not sufficient."11 A former chairman of the central ethical committee of the British Medical Association has suggested that the onus lies with doctors to obtain public involvement in the preparation of ethical guidelines. ${ }^{12}$

Two questions remain to be answered: has a prospective patient the right to express an opinion on his future medical management and, if so, in what form should the opinion be expressed ? Enormous improvements in the medical potential for sustaining life in both acute and long term care have aggravated the dilemma of when to stop. There is substantial evidence of an unchanging biological limit to the human life span of about 80-85 years, ${ }^{13} 14$ and it is predicted that the future pattern of medical care will show an acute compression of illness, largely brain failure, in the last few years of life. ${ }^{13}$ Such a pattern approaches the layman's ideal of a long healthy life and a brief dignified terminal illness. Unfortunately, at the end of life the doctors' two principal functions of curing disease and relieving suffering become increasingly incompatible. If belief in the sanctity of life prevails, there is no conflict of conscience, and maximum efforts at maintaining life are continued at all costs. This is the point at which the bemused public seems to want clarification of the objectives in medical care in old age and wants its own opinion to be heard. While many doctors may agree with Bayliss that one medical objective in the gravely ill is "to conform to the patient's expressed wishes,"10 the extent to which this should be pursued is far from clear. Kennedy is more explicit, and refers to professional hostility when "those outside medicine suggest how it ought to be practised." 15 The extent to which patients should be brought into moral and ethical decisions was discussed by Gillon: "If patients are given a genuine opportunity to indicate their preference, their autonomy is respected; but the doctrine of medical élitism forecloses their options and denies their autonomy."16

\section{Agreeing the limits of medical effort}

Western medicine seems to be moving into a phase in which the limits and limitations of treatment are being seen increasingly as the province not only of doctors but also of patients and relatives, lawyers and ethicists. It may be argued that, by and large, doctors do know when to stop "striving officiously," but the public perception of the limit may be different. Indeed it may be sufficiently different to require a greater medical awareness of the apparent need for dignity to be pursued as an aim in itself in advanced incurable illness. When it comes to the representation and expression of strongly felt wishes, a prior written declaration might be seen as one agency out of several which should be taken into account in life or death decisions in individual patients. The phrasing of a declaration should, as far as possible, be explicit, and it is suggested that its signature should be witnessed by the family doctor, this giving an opportunity to enlarge on the circumstances for its use. There is considerable evidence that, far from creating the fear of a sword of Damocles over a person's head, the preparation of a statement of wish (dubbed dignity document by the press) would relieve many elderly people of the nagging worry of indignity in a senile illness.

A move towards recognising and where appropriate implementing patients' wishes does not imply criticism of the practice of geriatric and psychogeriatric medicine, nor does it herald a move in the direction of active euthanasia. Beleaguered geriatricians, faced simultaneously with increasing pressure on beds, chronic lack of finance for appropriate institutional accommodation and diagnostic facilities, and difficulty in medical and nursing recruitment, deserve much greater professional and public support. Acheson finds the concept of the geriatrician as a clearer of blocked beds and the word geriatric itself to be derogatory and belittling. ${ }^{17}$ Perhaps the image could be altered by a move, supported by public, political, and medical opinion, towards greater identification of the specialty with the positive aspects of rehabilitation. In those patients in whom the prognostic indicators show little or no prospect of rehabilitation and who have expressed a wish to have life prolonging treatment withheld, ethical guidelines should be drafted to take account of such wishes.

The separate problems of terminology and interpretation make the composition of written statements doubly difficult, but the effort should be made. In a compelling editorial statement of 
the harsh truths pointing to the inevitability of the need to ration human life, at least within the context of American medicine, Lundberg ${ }^{18}$ concludes with a remark which is equally relevant to the need for Kuhse's "quality of life ethic"10: "One thing is certain. Reality cannot be delayed. Not to decide is to decide."

\section{References}

1 Robertson GS. Dealing with the brain-damaged old-dignity before sanctity. F Med Ethics 1982;8:173-9.

2 Anonymous. Organic mental impairment in old people [Editorial]. Lancet 1981 ;ii:561-2

${ }^{3}$ College Committee on Geriatrics of the Royal College of Physicians. Organic mental impairment in the elderly. $\mathcal{F} R$ Coll Physicians Lond 1981 ; 15:141-67.

- Smith JS, Kiloh LG. The investigation of dementia: results in 200 consecutive admissions. Lancet 1981 ; : :824-7.

- Thompson EG, Eastwood MR. Survivorship and senile dementia. Age Ageing 1981;10:29-32.
- Clarke MG, Williams AJ, Jones PA. A psychogeriatric survey of old people's homes. $\mathrm{Br}$ Med f 1981 ;283:1307-10.

7 Kellett JM. A new approach to the elderly. Br Med F 1982;285:1588-9.

8 McCall Smith A. Dignity and medical procedures. $\mathcal{F}$ Med Ethics 1981 ; 88-90.

- Eisendrath SJ, Jonsen AR. The living will. Help or hindrance ? $\mathcal{Y} A M A$ $1983 ; 249: 2054-8$

10 Bayliss RIS. Thou shalt not strive officiously. Br Med f 1982;285:1373-5.

11 Anonymous. Severely handicapped infants [Editorial]. F Med Ethics 1981; 7:115-6.

12 Thomas M. Should the public decide ? 7 Med Ethics 1981 ; 7:192-3.

13 Fries JF. Aging, natural death, and the compression of morbidity. $N$ Engl f Med 1980;303:130-5.

14 Gavrilov LA, Gavrilova NS, Nosov VN. Human life span stopped increasing: why ? Gerontology 1983;29:176-80.

15 Kennedy I. Doctors' dilemmas. The Listener 198310 Feb:8-9.

16 Gillon R. The function of criticism. Br Med f 1981;283:1633-9.

17 Acheson ED. The impending crisis of old age: a challenge to ingenuity. Lancet $1982 ; \mathrm{ii}: 592-4$.

18 Lundberg GD. Rationing human life. $\mathcal{F} A M A$ 1983;249:2223-4.

19 Kuhse H. Extraordinary means and the sanctity of life. $\mathcal{F}$ Med Ethics 1981; 7:74-9.

(Accepted 7 September 1983)

\title{
Lesson of the Week
}

\section{Hirschsprung's disease as a cause of chronic constipation in the elderly}

\author{
A J RICH, T W J LENNARD, J B WILSDON
}

Several large series of congenital megacolon have been described in infants. ${ }^{1}$ Severe cases do not survive infancy without surgery, but milder forms may remain undetected and present only in adult life, ${ }^{2}$ occasionally as a cause of chronic constipation. The number of histologically proved adult cases is small, and we describe here what is probably the oldest patient so far reported.

\section{Case report}

A 74 year old man was admitted for investigation of an abdominal mass, constipation, and weight loss. He gave a history of difficulty in defecation and abdominal distension since birth, and he had always had to use laxatives and enemas. Apart from this he had been healthy, moving his bowels with difficulty two or three times a week.

On examination, he was a thin man of average height in good general condition. His abdomen was distended with visibly dilated bowel and palpable stercoral masses. The rectum was of normal calibre and contained hard faecal pellets. Radiological examination confirmed a grossly dilated colon with faecal residues on plain radiographs and a barium follow through confirmed faecal obstruction of the colon. The mediastinum was shifted to the right. The possibility of adult Hirschsprung's disease was raised.

No spontaneous bowel action occurred, and enemas were administered to ease evacuation. Good results were obtained, but four days after admission he complained of sudden severe generalised abdominal

Royal Victoria Infirmary, Newcastle upon Tyne NE1 4LP A J RICH, MD, FRCS, lecturer in surgery

$T$ W J LENNARD, FRCs, lecturer in surgical science

J B WILSDON, DMRD, senior registrar in radiology

Correspondence to: Mr A J Rich.
Hirschsprung's disease should be considered in cases of chronic constipation, irrespective of the patient's age

pain and presented obvious signs of a perforated viscus. An emergency laparotomy was carried out. The whole of the colon was enormously dilated (figure) and thickened above a rectum of apparently normal calibre. The sigmoid loop lay under the left hemidiaphragm and had a stercoral perforation at its apex. At several points in the left and right colon longitudinal splitting of the muscle coats had occurred.

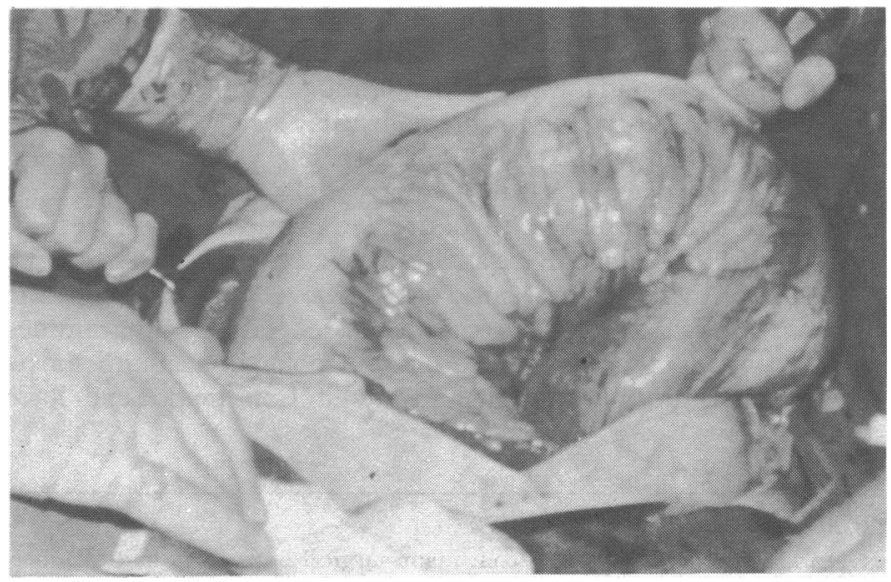

Sigmoid loop of colon presenting through incision.

$\underline{m}$ 